\title{
GÊNERO DIGITAL: A MULTIMODALIDADE RESSIGNIFICANDO O LER/ESCREVER ${ }^{1}$
}

\begin{abstract}
Francisca Francione Vieira de Brito $^{2}$
Maria Lúcia Pessoa Sampaio ${ }^{3}$

"Os gêneros não são entidades naturais como as borboletas, as pedras, os rios e as estrelas, mas são artefatos culturais construídos historicamente pelo ser humano." (Luiz Antonio Marcuschi).

"o hipertexto [...] forma de leitura self service [...] é o consumidor quem manuseia o cardápio, seleciona o hiperlink desejado para, em seguida, servir-se das iguarias mais apetitosas, na porção desejada, combinada com a velocidade do fluxo do pensamento." (Xavier, 2004, p.174).
\end{abstract}

\section{RESUMO}

$\mathrm{Na}$ contemporaneidade, as aplicações das Tecnologias de Informação e Comunicação mudaram as formas de pensar e atuar da humanidade, transcendendo barreiras físicas e temporais nas relações sociais de modo inimaginável. Considerando, pois, que as práticas de comunicação e interação social são inerentes ao processo educacional, o ensino vive um momento revolucionário que perpassa o binômio Pedagogia-Tecnologia e seus reflexos quanto ao ato do ler/escrever. O que antes era feito mecanicamente através de simples decodificação de signos lingüísticos, ou fluência na oralidade, agora excede a superficialidade material com a mediação de ferramentas digitais no uso da língua. Sendo assim, o objetivo deste artigo se assenta na abordagem da configuração textual dos gêneros digitais e subjacente renovação do ler/escrever na rede virtual. Para percorrer este trajeto discursivo nos reportaremos aos estudos do gênero em Bakhtin (1981, 2003), Marcuschi (2008), aos aportes teóricos quanto ao texto em Koch (2002), à teoria da multimodalidade de Kress \& Van Leeuwen com Dionísio(2005), ao ensino de leitura e escrita na escola com Zilberman (2009) fazendo ponte com os pressupostos defendidos por Kensky (2003) quanto a sua dinâmica no meio digital, dentre outros estudiosos. Constatamos, pois, que o objeto de estudo "texto" ganhou nova modelagem constitutiva e que, consequente, a forma de explorá-lo requer estratégias pedagógicas diferenciadas das empregadas até então no contexto escolar, no intuito de identificar e compreender as correlações de sentido do todo dialógico no interior da multiplicidade do gênero produzido e oferecido aos sujeitos leitores.

Palavras-chave: Gênero digital. Multimodalidade. Leitura/escrita. Ressignificação. 


\section{CONSIDERAÇÕES INICIAIS}

Com o boom tecnológico das últimas décadas e solidificação de seu "casamento" com a internet, todos os segmentos sociais sentiram o efeito dessa parceria, alguns de forma mais evidenciada que outros. Isso devido às inúmeras possibilidades de auxílio nas atividades diárias do homem. E a escola, como lócus de formação e aprendizagem humana, está imbricada nesta conjuntura de transformação. O conhecimento, hoje mais que nunca, é a principal matéria-prima de sobrevivência, e a busca do saber configura-se pela dinamicidade. Antes tínhamos "lugares do saber", agora temos "fontes".

$\mathrm{Na}$ contemporaneidade, as aplicações das Tecnologias de Informação e Comunicação - doravante TICs - mudaram as formas de pensar e atuar da humanidade, transcendendo barreiras físicas e temporais nas relações sociais de modo inimaginável. O que se vê na realidade atual "pode ainda parecer cenas de um filme de ficção" (TAJRA, 2008, p. 142) para muitos, mas, na verdade, é um convite a um mergulho neste mar de inovações que nos leva a caminhos outrora desconhecidos via rede mundial de navegação virtual.

Considerando, pois, que as práticas de comunicação e interação social são inerentes ao processo educacional, o ensino vive um momento revolucionário que perpassa o binômio Pedagogia-Tecnologia e seus reflexos quanto ao ato do ler/escrever. O que antes era feito mecanicamente através de simples decodificação de signos linguísticos ou fluência na oralidade foi ressignificado pela mediação de ferramentas digitais no uso da língua, excedendo assim a sua superficialidade material.

E o que isso quer dizer?

O objeto de estudo "texto" ganhou nova modelagem constitutiva e, consequente, a forma de explorá-lo requer estratégias pedagógicas diferenciadas das empregadas até então no contexto escolar, no intuito de identificar e compreender as correlações de sentido do todo dialógico no interior da multiplicidade do gênero produzido e oferecido aos sujeitos leitores.

Sendo assim, o objetivo deste artigo se assenta na abordagem da configuração textual dos gêneros digitais e subjacente renovação do ler/escrever na rede virtual. Para percorrer este trajeto discursivo nos reportaremos aos estudos do gênero em Bakhtin (1981, 2003), Marcuschi (2008), aos aportes teóricos quanto ao 
texto em Koch (2002), à teoria da multimodalidade de Kress \& Van Leeuwen com Dionísio (2005), ao ensino de leitura e escrita na escola com Zilberman (2009) fazendo ponte com os pressupostos defendidos por Kensky (2003) quanto a sua dinâmica no meio digital, dentre outros estudiosos.

\section{ACERCA DE GÊNERO}

Essa não é uma discussão nova. Muito se tem discutido sobre; havendo confusão, por parte de muitos, inclusive, com a correlata companheira de tessitura textual: a tipologia, comumente identificada por "tipos de texto" ${ }^{4}$. A efervescência dessas discussões quanto às teorias do gênero, sobretudo na Linguística Aplicada, pode estar centrada na menção feita pelos Parâmetros Curriculares Nacional (BRASIL, 1998) ${ }^{5}$ à sua importância nas atividades de leitura e produção textual ou ainda (o que é mais provável), ao enfoque dado, recentemente, à nova modelagem do texto através do domínio da mídia virtual como suporte. O consensual, entretanto, é a pluralidade de textos, orais e escritos, que materializam nossas relações sociais cotidianas por meio do uso da linguagem.

Para uma melhor noção sobre esse entorno, traçaremos um breve panorama acerca do gênero, desde os seus primórdios com as contribuições de Mikail Bakhtin. Vejamos:

Consagrado pelos pesquisadores como grande pioneiro nos estudos dos gêneros, em Estética da Criação Verbal, Bakhtin parte do uso multiforme da linguagem na atividade humana baseada na concretização de enunciados únicos, sejam orais ou escritos. Segundo ele, o emprego da língua é variável e está entrelaçado ao todo pelo conteúdo (temático), estilo (formal/informal) e composição (recursos lexicais, fraseológicos e gramaticais da língua) dos enunciados, conforme campo da comunicação; de modo a se constituir como tipos relativamente estáveis, denominados gêneros do discurso.

Sendo assim, na perspectiva bakhtiniana, pelo repertório infinito de possibilidades enunciativas não se pode pensar numa singularidade de gêneros e sim, em sua heterogeneidade. No plano do estudo desses fenômenos heterogêneos, durante a antiguidade, se explorava, primeiramente os gêneros retóricos e depois os do cotidiano, surgindo, pois, a necessidade de classificá-los em primários (simples) e 
secundários (complexos). Estes surgem nas condições de convívio social relativamente desenvolvida e organizada (artístico, científico, sociopolítico etc.) e aqueles se formam em condições de comunicação discursiva imediata. Os primários incluem, por exemplo, o diálogo cotidiano; os secundários englobam os romances, as pesquisas científicas, entre outros gêneros oriundos de situações sociais mais complexas. Nessa perspectiva, os primeiros podem integrar os segundos.

Conforme os preceitos de Bakhtin (2003), a diferença ideológica entre os gêneros primários e secundários é grande e por isso deve-se estudar a natureza constitutiva e particularidades de cada modalidade, norteado pela noção de enunciados como "unidade real da comunicação discursiva"; isto permitirá compreender melhor as unidades da língua, a história da linguagem e da sociedade na atividade humana, situando-a no campo da (meta)linguística e da filologia.

Portanto, entender a linguagem como tal é admitir que "a língua passa a integrar a vida através de enunciados concretos (que a realizam); é igualmente através de enunciados concretos que a vida entra na língua. O enunciado é um núcleo problemático de importância excepcional”, afirma Bakhtin (2003, p. 265).

Passemos, agora, à explanação de outras contribuições teóricas sobre gênero.

Muitos são os pesquisadores que se debruçam sobre o estudo dos gêneros, culminando em duas vertentes teóricas: gêneros do discurso (firmados nas premissas de Bakhtin e seu Círculo) e gêneros de texto (baseados nos preceitos de Bronckart e Adam). Para estas, também são usadas, respectivamente, as terminologias "gêneros discursivos" e "gêneros textuais". Quanto à classificação, há os que divergem - como Mainguenau (2008) e Fairclough (2001) - e as coloca como equivalentes, considerando que um evento discursivo é simultaneamente um texto na prática social e, portanto, um texto de um gênero do discurso.

Mas nessa perspectiva dicotômica, qual seria o objeto de estudo de cada teoria?

Segundo (ROJO, 2005, p. 185), a teoria dos gêneros discursivos está centrada na situação de produção onde as marcas linguísticas dos enunciados produzem significações considerando seus aspectos sócio-históricos no discurso; já a teoria dos gêneros de texto descreve a tessitura material do texto (forma, propósito comunicativo, sequência tipológica) com base nas noções herdadas da Linguística 
Textual. Supostamente são ângulos distintos que se complementam de alguma maneira na aplicabilidade das unidades concretas de realização da língua.

E qual é a distinção, então, entre "texto" e "discurso"?

Para Marcuschi (2008, p. 24) "pode-se dizer que texto é uma entidade concreta realizada materialmente e corporificada em algum gênero textual. Discurso é aquilo que um texto produz ao se manifestar em alguma instância discursiva. Assim, o discurso se realiza nos textos". Temos, na verdade, pontos intercessores que resultam em "duas faces da mesma moeda" de um gênero como entidade dinâmica concretizada na linguagem, através de formas culturais e cognitivas de ação social e não em modelos estanques.

Seguindo este norte, Marcuschi (2008, p. 149) complementa:

[...] a análise dos gêneros engloba uma análise do texto e do discurso e uma descrição da língua e visão da sociedade, e ainda tenta responder a questões de natureza sociocultural no uso da língua de maneira geral. $O$ trato dos gêneros diz respeito ao trato da língua em seu cotidiano nas mais diversas formas. E se adotarmos a posição de Carolyn Miller (1984), podemos dizer que os gêneros são uma forma de ação social. Eles são um artefato cultural importante como parte integrante de nossa sociedade.

Assim, a concepção de um gênero ocorre pela necessidade das situações de interação social, os gêneros vão se moldando e se estabilizando nas atividades de comunicação humana à sua maneira, sem ser possível controlá-los e/ou determinálos; surgem naturalmente na manifestação das realizações de exercício do poder da linguagem - histórica e concreta em sua essência. Com a nova cultura eletrônica cristalizada na sociedade, por exemplo, outros gêneros apareceram como transmutações de gêneros já existentes, sendo arriscado tentar classificá-los, por seu caráter de flexibilidade - sobretudo àqueles provenientes do uso das tecnologias nas relações de saber. Temos os chamados "gêneros digitais" ou "emergentes".

Em consonância com essa caracterização de maleabilidade dos gêneros, Marcuschi (2004) citado por Pereira \& Penha (2008, p. 4) salienta:

\footnotetext{
Os gêneros adaptam-se, renovam-se e multiplicam-se e devem ser estudados na relação com as práticas sociais, os aspectos cognitivos, os interesses, as relações de poder, as tecnologias, as atividades discursivas e no interior da cultura. Mudam, fundem-se para manter sua identidade funcional com inovação organizacional. Nem são estáticos, nem puros, são formações interativas, multimodalizadas e flexíveis de organização social que contribuem para ordenar e estabilizar as atividades comunicativas do dia-a-dia.
} 
Com o advento da Internet aliada às TICs, a linguagem - tomando como ponto de partida a escrita - passou a ser, na contemporaneidade, peça propulsora na interligação do sistema de rede conectada aos meios eletrônicos, ganhando um novo estilo constitutivo marcado por formas híbridas de texto que misturam sons, imagens, palavras (recursos verbais e não-verbais) num mesmo espaço virtual. Logo, o objeto texto ganhou uma "repaginada" em sua arquitetura de modo que os gêneros digitais passaram a firmar-se em teorias além Linguística do Texto, com evidência num olhar semiótico sobre a expressão da linguagem dentro do social. É o que veremos a seguir.

\section{O TEXTO HOJE: SOB A ÓTICA DA MULTIMODALIDADE}

Pelo exposto, vimos que hoje em dia, o conceito de texto está intrinsecamente ligado ao discurso, ou seja, o texto corresponde a uma situação dialógica, na qual se manifestam elementos linguísticos e extralinguísticos, codificados pela gramática e realizados conforme contrato comunicativo, ou seja: de acordo com a sua finalidade de produção. O texto é um lugar de correlações entre as operações e estratégias produtoras de seu sentido.

Diante dessas transfigurações da noção do objeto texto, concomitantemente, também mudaram a prática de leitura e o perfil do leitor atual; e de sobremaneira do leitor-navegador, que usa a internet como fonte de informação, mantendo contato com os mais diversos gêneros digitais. Em outros termos, o ato de ler se transformou historicamente com a aparição do texto eletrônico, que traz consigo uma nova forma de linguagem mesclando o oral, o escrito, o imagético e o digital. Como bem caracteriza Rocco citado por Kensky (2003, p. 62) "O texto eletrônico é um produto verbal diferente, um produto de um novo tempo, veiculado por um novo suporte que atua [...] sobre os processos de apropriação e significação por parte dos leitores. Trata-se de um texto híbrido[...]".

É, pois, neste ponto da pluralidade do texto, na sua diversidade de forma e conteúdo, que se assenta a "teoria da multimodalidade" ou "semiótica", bastante em voga atualmente com a abrangência das mídias eletrônicas e dinamicidade intrínseca ao valor informativo das mesmas. Subjacente a ela, emerge a "gramática do design visual", tida como base de apoio aos muitos pesquisadores que se dedicam a analisar os recursos multimodais como objeto de interesse investigativo 
na constituição de textos e produção de seu sentido a partir de diversos modos da linguagem.

Postulada por Kress e Van Leeuwen em 2001, a teoria da modalidade, de acordo com Sperandio (2012, p. 3), está firmada numa abordagem linguística sociointeracionista, em que

\begin{abstract}
os autores baseiam-se em uma ideia de prática e ancoram-se na noção de uso de uma variedade de recursos semióticos utilizados na produção do signo em contextos sociais concretos. Sendo esses signos baseados em significantes como cores, perspectivas e linhas; que são utilizados na representação material dos significados. Para os autores, diferente do que propõe a semiologia tradicional que concebia os signos a partir de uma dupla articulação entre o significante (imagem acústica, as formas) e o significado (sentidos), essa articulação não basta para que sua constituição seja satisfatoriamente entendida.
\end{abstract}

Nesse sentido, parafraseando Almeida (2009) citado por Mota (2011, p. 4) a proposta sociossemiótica de Kress e Van Leeuwen envolve a descrição analítica dos dados do nível microtextual à esfera macrotextual na busca dos significados socioculturais da tessitura textual. Assim, não é preciso muito esforço para constatarmos a presença de textos cada vez mais multimodais, circulando e/ou sendo produzidos entre/por nós nas diversas situações comunicativas da vida social. São textos onde coexistem diferentes níveis semióticos, como o visual, sonoro, gestual, etc. conferindo significados específicos à linguagem. Esse quadro situacional se configura nitidamente nos gêneros digitais blog, twitter, e-mail, MSN, por exemplo. Para Kress e Van Leeuwen trata-se de um momento denominado New Writing.

Sobre esse uso acentuado de recursos multimodais, afirma Dionísio (2005, p.159-160):

Com o advento de novas tecnologias, com muita facilidade se criam novas imagens, novos layouts, bem como se divulgam tais criações para uma ampla audiência. Todos os recursos utilizados na construção dos gêneros textuais exercem uma função retórica na construção de sentido dos textos. Cada vez mais se observa a combinação de material visual com a escrita; vivemos, sem dúvida, numa sociedade cada vez mais visual. Representação e imagens não são meramente formas de expressão para divulgação de informações, ou representações naturais, mas são, acima de tudo, textos especialmente construídos que revelam as nossas relações com a sociedade e com o que a sociedade representa.

Dentro dessa natureza digital semiolinguística, surge um dispositivo multimodal: o hipertexto - considerado por Kensky (2003, p. 62) "um caminho para a informação". Por hipertexto entende-se o texto disponibilizado em espaço virtual que 
permite uma leitura não linear, em função de sua organização em blocos de conteúdo que se conectam por elos hipertextuais, também conhecido como links trazendo em seu bojo elementos verbais, imagéticos, sonoros. Na óptica de Lévy (1993) citado por Gonçalves \& et al.. (2012, p. 387) trata-se de "um conjunto de nós ligados por conexões. Os nós podem ser palavras, páginas, imagens, gráficos ou partes de gráficos, sequências sonoras, documentos complexos que podem eles mesmos ser hipertextos".

É importante salientar que mesmo com a possibilidade de integração de imagens e sons, a escrita continua sendo a base na Internet. É esta a modalidade linguística predominante nas interações comunicativas, embora alguns prefiram o uso da expressão "fala por escrito" ou ainda "escrita da fala". Talvez por isso algumas peculiaridades tenham se mostrado na conjuntura da linguagem virtual, como por exemplo: inserção de smyles, economia na forma da escritura de textos digitais e ainda a incorporação de um léxico específico do próprio meio informacional ao vocabulário de seus usuários (como ocorre em determinada área técnica). Hoje faz parte do cotidiano de muitos, palavras tipo: e-mail, on-line, deletar, clicar, escanear, algumas já registradas em dicionários de circulação nacional.

Contudo, na faceta linguagem na internet/ internet na linguagem e considerando a concepção de língua como um lugar de interação humana, defendida por Bakhtin (1981), é imprescindível que os sujeitos socio-históricos se tornem atores competentes pragmática e tecnologicamente dentro desta nova modelagem cultural da contemporaneidade, sendo capazes de compreender e subtrair sentido dessa multiplicidade de signos semióticos dos gêneros digitais, indo além da mera transmissão de informação no momento da leitura/escrita hipertextual. Sobre esta prática nos deteremos a partir de agora com mais veemência.

\section{DAS PÁGINAS À TELA: LEITURA E ESCRITA, COMO VÃO?}

Como se assenta a leitura/escrita hoje? E sua prática nesse contexto eletrônico como ocorre? Qual o perfil do leitor multimodal? Quais as competências necessárias ao leitor digital?

Refletir sobre essas questões torna-se não só pertinente na atualidade, mas, sobretudo, urgente diante da reconfiguração textual na comunicação humana "que, no mundo digital, ganhou formas móveis e inconstantes" como diz Zilberman (2009, 
p. 22). A referida autora cita o exemplo das transformações de gêneros tradicionais quando migram do livro para a Internet (das páginas à tela) suscitando novas formas de expressão, dentre as quais a mais desafiadora é o hipertexto - composto de blocos de texto aonde o leitor-usuário vai criando sua trilha de leitura ao ligar um pedaço de informação a outro através de um arranjo não linear para inferir-lhe um sentido.

Mas, e a leitura/escrita em geral, como vão?

O ato de ler/escrever é de suma importância em todos os níveis educacionais, pois se constitui como uma forma de interação entre os homens em qualquer área do conhecimento permeada pelo objeto língua, possibilitando-lhes a aquisição de diversos pontos de vista, ampliação de experiências e transmissão e transformação cultural numa dialética entre o "eu" e o "outro". Entretanto, basta uma simples observação empírica, para percebermos o desestímulo e/ou "desgosto" dos sujeitos aprendizes pela prática de leitura/escrita devido à metodologia inadequada ainda utilizada em muitos ambientes escolares, baseada numa abordagem mecânica de decodificação de signos linguísticos e/ou performance automatizada do "dizer", sem considerar sua axiologia polissêmica nem o contexto de concepção do texto.

Contudo, hoje, muitos são os públicos sociais já envolvidos cotidianamente na prática de leitura e produção de gêneros textuais/discursivos via suportes digitais de sobremaneira os estudantes jovens. A velocidade, versatilidade e atratividade das TICs seduziu os visitantes do ciberespaço no estabelecimento de interações comunicativas e acesso a uma miríade de informações de tal maneira que ressignificou o ato de ler/ escrever na vida contemporânea. Assim, o hipertexto imergiu os sujeitos numa revolução social e linguística irreversível.

Nas modalidades de leitura e escrita da sociedade multimodal, como afirma Elias (2005), o texto é "aberto" - ou ainda, "promíscuo" - dada à sua permissão de manipulação dos hiperlinks por parte do leitor e mergulhar nos dados ali disponíveis combinando as informações de modo digital. Como bem acrescenta Xavier (2003, p. 186) "essa 'abertura' acontece porque o hipertexto é, 'fisicamente', acolhedor, ele hospeda 'materialmente' outras obras hipertextualizadas. Ele absorve a essência de outros hipertextos, por isso tende a apagar as fronteiras".

Destarte, o leitor tem mais liberdade para escolher, dentre os caminhos oferecidos pelo autor, em que aspectos aprofundar sua leitura, que blocos de conteúdo ignorar ou retomar, que sugestões de conexão externa acatar. 
Parafraseando Xavier (2003), vemos a partir deste esboço a instabilidade do texto e o declínio da autoridade do autor se configurar. Em verdade, o leitor se torna o protagonista do processo da construção de sentidos nessa leitura vertical , uma vez que, "explora o capital de significação do que lê, valoriza o potencial da produção com a qual interage, adensa, portanto, sua identidade leitora e sua responsividade ao texto" (AMARILHA,2010, p. 1).

O leitor da escrita digital faz de seus interesses e objetivos o fio organizador das escolhas e ligações, procedendo por associações de idéias que o impelem a realizar sucessivas opções e produzindo, assim, uma textualidade cuja coerência acaba sendo uma construção pessoal, pois não haverá efetivamente dois textos exatamente iguais na escritura hipertextual. $(\mathrm{KOCH}, 2002$, p. 72).

Na chamada "era digital", o conceito de escrita se expandiu e não diz mais respeito apenas ao texto impresso. É necessário saber se relacionar com a mesma nas diversas mídias em que ela se faz presente; pois novas maneiras do ato de ler, e simultaneamente de produzir textos, foram criadas, exigindo dos sujeitos outras competências além das linguísticas para que sejam capazes de compreender a função da multiplicidade de formas da língua. Assim, conhecer as possibilidades de leitura e construção de sentidos permeados pela tecnologia digital perpassa por uma compreensão da concepção de linguagem na atualidade que exige dos cibernautas um "letramento digital" para que se tornem home zapin ${ }^{6}$ competentes. Verdadeiros hiperleitores!

A título de esclarecimento dos pressupostos teóricos aqui expostos, analisemos brevemente os seguintes exemplos de gêneros digitais multimodais: Postagem feita pelo Bloguinfo ${ }^{7}$ (http://bloguinfo.blogspot.com.br/) sobre "Hipertextualidade na Educação" e ainda bate-papo em rede social. Vamos ao primeiro: 


\section{Figuras 1 e 2}
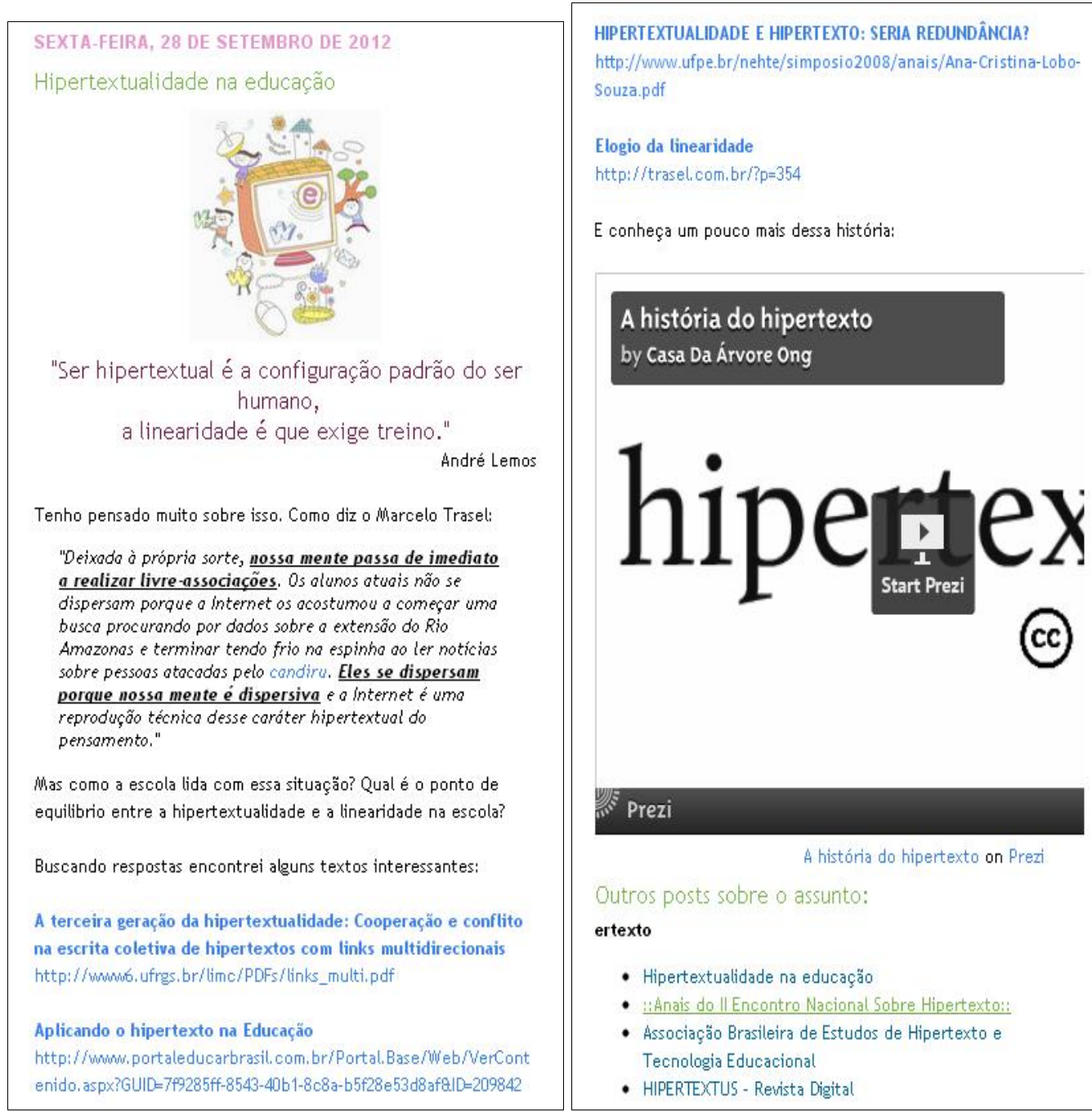

Prezi

A história do hipertexto on Prezi

\section{Outros posts sobre o assunto:}

ertexto

- Hipertextualidade na educação

- Anais do ll Encontro Nacional Sobre Hipertexto::

- Associação Brasileira de Estudos de Hipertexto e

Tecnologia Educacional

- HIPERTEXTUS - Revista Digital

Fonte: http://bloguinfo.blogspot.com.br/2012/09/hipertextualidade-na-educacao.html

Vemos pelas imagens da postagem que a mesma apresenta uma dinamicidade na abordagem do conteúdo, mesclando texto verbal e visual, com blocos marcados por links que encaminham o leitor a outras fontes sobre o assunto, disponibilizando ao hiperleitor, inclusive, um arquivo em formato Prezzi (em sua essência, caracterizado pelo movimento interativo) versando sobre $A$ história do hipertexto. Há ainda a disponibilidade de acesso a endereços eletrônicos de eventos específicos que, por sua vez, leva o usuário virtual aos trabalhos apresentados durante estes. Além disso, temos na página deste gênero digital sessões como: sugestões de ideias e blogs, trabalhos da autora on-line, livro de visitas, dentre outros tópicos. Aqui, o leitor tem liberdade para escolher o percurso a seguir via recursos multimodais e criar, assim, o seu próprio texto condicionado pela leitura. 
Analisemos um exemplo de outro gênero digital: o bate-papo ${ }^{8}$ na rede social facebook.

\section{Figuras 3 e 4}

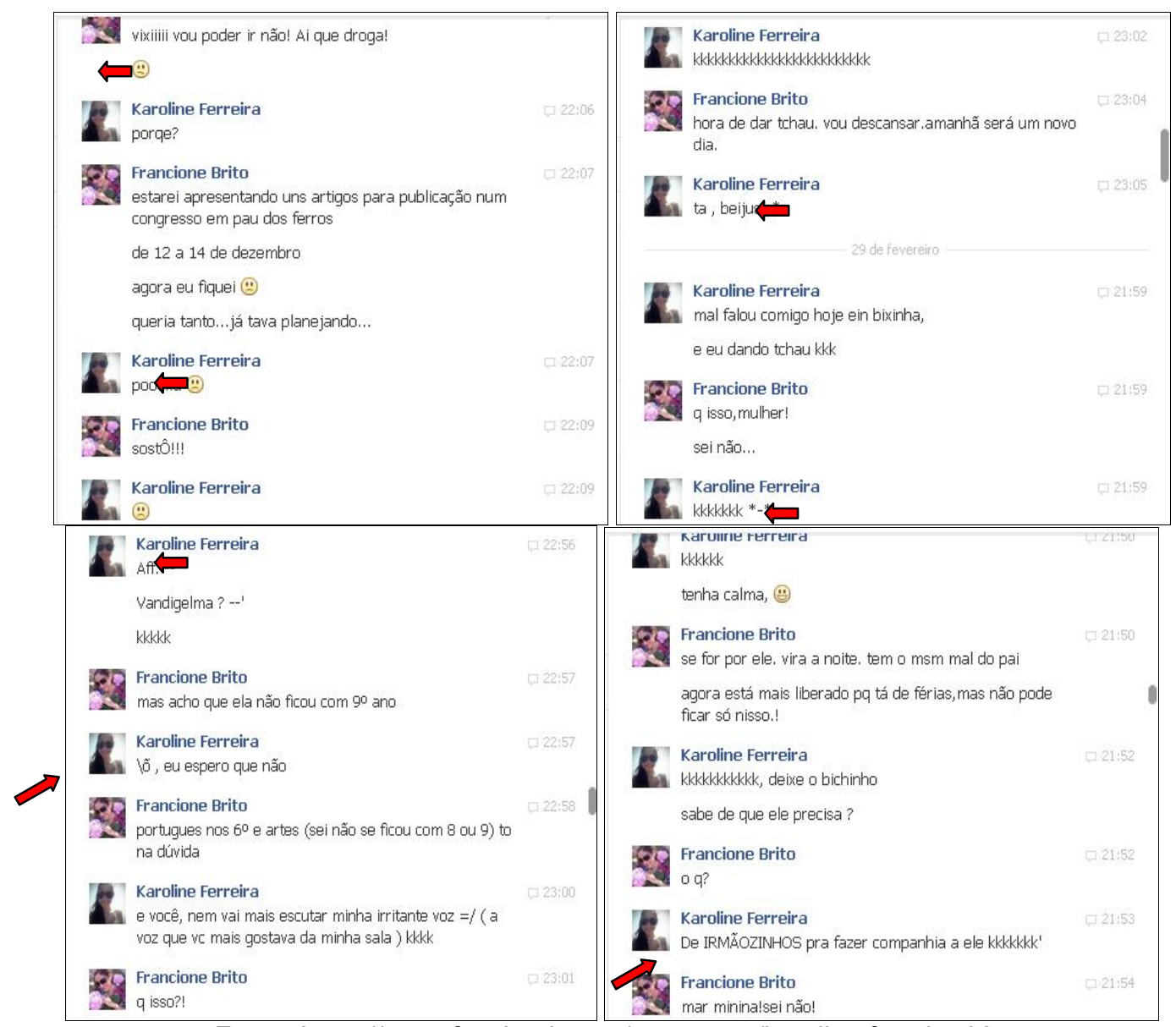

Fonte: https://www.facebook.com/messages/karoline.ferreira.927

Pelas marcações, percebemos claramente a inserção de um código linguístico específico na conversão digital que ganha vida numa dinâmica de transmutação da oralidade à virtualidade, onde o silêncio da fala dá vez ao barulho do teclado permeado pela expressividade através de símbolos (emotions) e economia de signos linguísticos. Vemos ainda, no exemplo do bate-papo estabelecido, significações particulares no formato da fonte utilizada em determinado trecho (letra maiúscula quando se quer gritar e/ou dizer com veemência), as onomatopeias do riso e aborrecimento (kkkkkkkkk / aff), bem como a representação de sujeito feliz e/ou na torcida (Iõ).

É a "linguagem moderna" se manifestando na comunicação virtual. Vivenciar essa modernidade não é um "capricho" humano, mas uma necessidade aos que não 
querem ficar "perdidos" no tempo. Conhecer os contextos, para saber interagir na sociedade. É isso!

\section{CONSIDERAÇÕES FINAIS}

Desde muito a comunicação é a base das interações humanas e se concretiza por algum gênero textual/discursivo. Com o aparecimento do ciberespaço, a linguagem - objeto das manifestações comunicativas - sofreu variações de usos, tornando-se mais dinâmica, versátil, atrativa e flexível a depender do suporte material de veiculação. Os reflexos dessa modernidade tecnológica foram refletidos no âmbito educacional, exigindo dos sujeitos envolvidos regular o periscópio das estratégias para a busca do saber e assim responder satisfatoriamente às demandas da sociedade circundante. Assim, 0 ato de ler/escrever foi ressignificado pela dinamicidade da agregação de recursos multimodais aos gêneros digitais.

Contudo, somente a articulação de signos semióticos e linguísticos na tessitura composicional de textos discursivos não basta para a efetivação da produção do(s) sentido(s) em contextos sociais concretos de interação social. O aproveitamento dos suportes tecnológicos na prática de leitura e escrita é de grande importância como "isca" para envolver e estimular os sujeitos aprendizes na construção de saberes que the são essenciais, mas o crivo, assim como no trabalho com o texto em páginas de papel, está no planejamento de atividades relevantes nos ambientes virtuais. Como disse Silva (2010, p. 7) "a Web é um grande e fértil terreno para a aprendizagem dos alunos; terreno este que deve ser 'pisado' com cuidado, observando todas as possíveis rotas".

Os estudos mediados pela leitura/escrita pressupõem o estabelecimento de relações. Os gêneros digitais nos exigem o mesmo: transitamos entre palavras, imagens e sons aguçando nossa capacidade de estímulo sensorial, intelectual e comunicacional para encontrar no labirinto eletrônico do hipertexto a solidificação do conhecimento, buscado pela autonomia das escolhas no itinerário percorrido.

Portanto, a tecnologia motiva, mas não é a solução. O uso rotineiro das práticas cibernéticas que envolvem leitura e escrita não necessariamente representa uma melhoria relevante e/ou qualidade nessas atividades para os usuários da rede. Levá-los a um laboratório de informática para que saiam assim como entraram é 
inútil. É necessário promover o discernimento do ato de ler/escrever dentro e fora da web, enxergar velhos problemas com novas perspectivas. A tecnologia, hoje, é um meio do profissional educador (auto) sensibilizar, (auto) conscientizar, orientar o hiperleitor a permanecer on-line efetivamente nessa cadeia de aprendizagem constante, em que ambos se igualam na interação comunicativa permeada pelo uso da linguagem em sua pluralidade de gêneros.

\section{NOTAS}

1 A construção deste texto teve sua origem a partir das exigências de conclusão da disciplina "Linguagem e Discurso", ministrada pela professora Dra. Maria do Socorro Maia Barbosa no Programa de Pós-Graduação em Letras - PPGL do Campus Avançado Profa. Maria Elisa de Albuquerque Maia - CAMEAM da Universidade do Estado do Rio Grande do Norte - UERN em Pau dos Ferros-RN, durante o semestre 2012.1, cujo objetivo foi discutir acerca dos estudos da linguagem, sob a ótica do sociointeracionismo, envolvendo abordagens sócio-culturais, textuais e discursivas e a análise de textos e discursos.

2 Graduada em Letras com Habilitação em Língua Espanhola e respectivas Literaturas pela Universidade do Estado do Rio Grande do Norte-UERN (2003). Especialista em Leitura e Produção Textual pela mesma IES e ainda em Língua Espanhola pela Faculdade do Vale do Jaguaribe - FVJ.

3 Graduada em Pedagogia pela Universidade do Estado do Rio Grande do Norte (1992), com Especialização, Mestrado e Doutoramento no Programa de Pós-Graduação em Educação da Universidade Federal do Rio Grande do Norte (1999-2005). Pós-Doutoramento no Laboratoire d'Etudes Romanes, na Équipe de Linguistique des Langues Romanes na Université Paris 8, France (2010-2011). Professora adjunto IV do Departamento de Educação e Bolsista de Produtividade da Universidade do Estado do Rio Grande do Norte, desde 2007.

\footnotetext{
${ }^{4}$ Por não ser este o foco da nossa pesquisa, não vamos adentrar na discussão, mas apenas apontar sua significação básica com base em Marcuschi (2008, p. 154): "Tipo textual designa uma espécie de construção teórica definida pela natureza linguística de sua composição (aspectos lexicais, sintáticos, tempos verbais, relações lógicas, estilo)". Para a noção de tipo textual, predomina a identificação de sequências linguísticas como norteadoras, inclui a narração, a argumentação, a descrição, a exposição e a injunção; ressaltando que o conjunto de categorias para designar os referidos tipos é limitado e sem tendência a aumentar:

${ }^{5}$ Nessa perspectiva, necessário contemplar, nas atividades de ensino, a diversidade de textos e gêneros, e não apenas em função de sua relevância social, mas também pelo fato de que textos pertencentes a diferentes gêneros são organizados de diferentes formas. A compreensão oral e escrita, bem como a produção oral e escrita de textos pertencentes a diversos gêneros, supõem o desenvolvimento de diversas capacidades que devem ser enfocadas nas situações de ensino. É preciso abandonar a crença na existência de um gênero prototípico que permitiria ensinar todos os gêneros em circulação social (p. 23/24).
}

${ }^{6}$ Designação utilizada por Amarilha (2010, p. 2) para fazer referência ao leitor que transita de um material a outro em consonância com a dinâmica da multimodalidade na formação do leitor contemporâneo.

7 Escrito por Sintian Schmidt, professora das séries iniciais do Ensino Fundamental e Assessora Pedagógica de Informática Educativa em Caxias do Sul - RS, desde 2006. 
${ }^{8}$ Diálogo entre a pesquisadora e uma ex-aluna na rede social (por ser participante não foi usado nome fictício).

\title{
GÉNERO DIGITAL: LA MULTIMODALIDAD RESIGNIFICANDO EL LEER/ESCRIBIR
}

\begin{abstract}
RESUMÉN
Hoy en día, las aplicaciones de tecnologías de la información y la comunicación han cambiado la forma de pensar y actuar de la humanidad, más allá de las barreras físicas y temporales en las relaciones sociales de manera inimaginable. Considerando, por tanto, que la práctica de la comunicación y la interacción social son inherentes al proceso educativo, la escuela está pasando por un momento revolucionario que se respira en el binomio Pedagogía-Tecnología y sus reflexiones sobre el acto de lectura / escritura. Lo que se hizo mecánicamente por simple descodificación de signos lingüísticos o fluidez oral, ahora excede a la superficialidad material con la mediación de herramientas digitales en el uso de la lengua. Por lo tanto, el propósito de este artículo se basa en el enfoque de configuración de los géneros textuales digitales y subyacente renovación de lectura / escritura en la red virtual. Para recorrer este camino discursivo aludiremos a los estudios de género en Bakhtin (1981, 2003), Marcuschi (2008), las aportaciones teóricas sobre el texto de Koch (2002), la teoría de la multimodalidad Kress y Van Leeuwen con Dioniso (2005), a la enseñanza del leer / escribir en la escuela con Zilberman (2009) haciendo puente con los presupuestos defendidos por Kensky (2003) cuanto a su dinámica en el medio digital, entre otros estudiosos. Comprobamos, por tanto, que el objeto de estudio "texto" ganó nuevos modelos constitutivos y, en consecuencia, la forma de explotarlo requiere estrategias de enseñanza distintas de las empleadas hasta ahora en el contexto de la escuela con el fin de identificar y comprender el las correlaciones de sentido del todo dialógico en el interior de la multiplicidad del género producido y ofrecido a los sujetos lectores.
\end{abstract}

Palabras-Ilave: Género digital. Multimodalidad. Lectura/escritura. Resignificación.

\section{REFERÊNCIAS}

AMARILHA, Marly. A multimodalidade na formação do leitor contemporâneo. In: $62^{a}$ REUNIÃO ANUAL DA SBPC. Mesa-redonda: a formação do leitor no século XXI, jul. 2010, Natal, RN . Anais... Disponível em:

<http://www.sbpcnet.org.br/livro/62ra/mesas_redondas/MR\%20Marly\%20Amarilha.p df>. Acesso em: nov. 2012.

BAKHTIN, Mikail. Marxismo e filosofia da linguagem. Trad. M. Lahud e Y. F. Vieira. São Paulo: Hucitec, 1981.

. Estética da criação verbal. São Paulo: Martins Fontes, 2003. 
DIONISIO, Ângela Paiva. Gêneros multimodais e multiletramento. In: KARWOSKI, A.M.; GAYDECZKA, B.; BRITO, K.S. (Orgs.). Gêneros textuais: reflexões e ensino. Palmas e união da Vitoria, PR: Kaygangue, 2005.

ELIAS, Vanda Maria da S. Hipertexto, leitura e sentido. Revista de Linguística Aplicada Calidoscópio, São Leopoldo: UNISINOS, v. 3, n. 1, janeiro/abril de 2005. Disponível em:

<http://www.pucsp.br/pos/lgport/downloads/publicacao_docentes/hipertexto_vanda.p df>. Acesso em: 08 out. 2012.

GONÇALVES, Â. I.; SANTOS, G. da S. dos; MARCHESAN, M. T. N. O hipertexto e a não linearidade textual como agente facilitador da aprendizagem. Revista Signo.

Santa Cruz do Sul, v. 37 n. 62, p. 381-395, jan./jun. 2012. Disponível em:

<http://online.unisc.br/seer/index.php/signo>. Acesso em: nov. 2012.

KENSKY, Vani Moreira. Tecnologias e ensino presencial e a distância. Campinas: Papirus, 2003.

$\mathrm{KOCH}$, Ingedore Grunfeld Villaça. Desvendando os segredos do texto. São Paulo: Cortez, 2002.

MARCUSCHI, Luiz Antonio. Produção textual, análise de gêneros e compreensão. São Paulo: Parábola, 2008.

MOTA, Fabrício Paiva. Estudo de um blog educacional de língua espanhola sob a perspectiva da teoria da multimodalidade: o valor informativo. Hipertextus, v. 6, ago. 2011, p. 4 Disponível em: <http://www.hipertextus.net/volume6/Hipertextus-Volume6Fabricio-Paiva-Mota.pdf>. Acesso em: nov. 2012.

BRASIL. Secretaria de Educação Fundamental. Parâmetros curriculares nacionais: terceiro e quarto ciclos do ensino fundamental: língua portuguesa. Brasília: MEC/SEF, 1998.

PENHA, D. T. da .; PEREIRA, J. S. Ferramentas do Orkut: inovação tecnológica a favor do gênero textual. COLÓQUIO NACIONAL DE LINGUAGEM E DISCURSO CONLID, 2008, Mossoró. Anais...Disponível em: $<$ http://anaisdoconlid1.blogspot.com.br/2011/09/ferramentas-do-orkutinovacao.html>. Acesso em: nov. 2012.

ROJO, Roxane. Gêneros do discurso e gêneros textuais: questões teóricas e aplicadas. In: MEURER, J.L.; BONINI, A.; MOTTA-ROTH, D. (Orgs.). Gêneros: teorias, métodos e debates. São Paulo: Parábola Editorial, 2005. p. 184-207.

SILVA, Érika Suellem Castro da. Leitura e escrita no ciberespaço: desafios ao professor de línguas. Hipertextus, v. 4, jan. 2010. Disponível em:

<http://www.hipertextus.net/volume4/Erika-Suellem-Castro-SILVA.pdf>. Acesso em: nov. 2011.

SPERANDIO, Natália Elvira. Multimodalidade e processamento metafórico em um texto digital: abordando o sentido a partir da interação entre o verbal e o imagético. 
Hipertextus, v. 8, jun. 2012, p. 3. Disponível em:

<http://www.hipertextus.net/volume8/06-Hipertextus-Vol8-Natalia-ElviraSperandio.pdf>. Acesso em: nov. 2012.

TAJRA, Sanmya Feitosa. Informática na educação: novas ferramentas pedagógicas para o professor na atualidade. 8. ed. rev. e ampli. São Paulo: Érica, 2008.

XAVIER, Antonio Carlos. dos Santos. Hipertexto e Pós-Modernidade. Revista Investigações: Linguística e Teoria literária, Recife, v. 16, n. 2, 2003.

ZILBERMAN, Regina. A leitura no mundo digital. Revista Signo, Santa Cruz do Sul, v. 34 n. 56, p. 22-32, jan./jun. 2009. Disponível em:

<http://online.unisc.br/seer/index.php/signo/article/viewFile/960/681>. Acesso em: nov. 2012. 